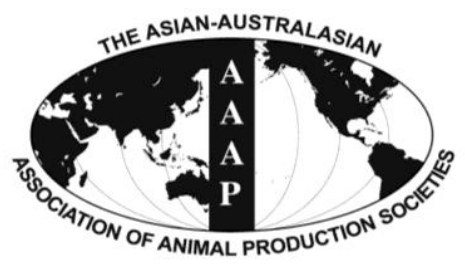

Asian-Aust. J. Anim. Sci.

Vol. 25, No. $7: 1003$ - 1008 July 2012

www.ajas.info

http://dx.doi.org/10.5713/ajas.2011.11402

\title{
Effect of Medium-chain Triglyceride (MCT) on Growth Performance, Nutrient Digestibility, Blood Characteristics in Weanling Pigs
}

\author{
S. M. Hong, J. H. Hwang ${ }^{1}$ and I. H. Kim* \\ Department of Animal Resource and Science, Dankook University, Cheonan, Choognam 330-714, Korea
}

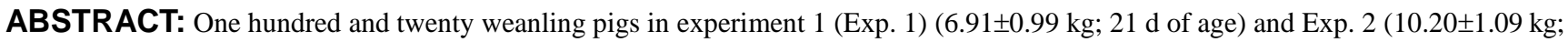
$28 \mathrm{~d}$ of age) were used in two 42-d and 35-d experiments to evaluate the effect of medium-chain-triglyceride (MCT) on growth performance, apparent total tract digestibility (ATTD) of nutrients and blood profile. In both of Exp. 1 and Exp. 2, the same dietary treatments were utilized as follows : i) negative control (NC), ii) positive control (PC), NC+antibiotics (40 mg/kg Tiamulin, $110 \mathrm{mg} / \mathrm{kg}$ Tylosin, and $10 \mathrm{mg} / \mathrm{kg}$ Enramycin, iii) MCT3, NC+0.32\% (phase 1, 2 and 3) MCT, and iv) MCT5, NC+0.55\% (phase 1), 0.32\% (phase 2 and 3) MCT. In Exp. 1, the pigs fed MCT5 diets had higher ( $\mathrm{p}<0.05)$ ADG compared to NC treatment during the first 2 wk. From d 15 to 28 , the ATTD of energy was improved $(\mathrm{p}<0.05)$ by MCT3 compared to the PC treatment. No effect has been observed on the blood profiles [red blood cell (RBC), white blood cell (WBC), immunoglobulin-G (IgG), lymphocyte concentration] measured in this study. In Exp. 2, the ADG were increased $(\mathrm{p}<0.05)$ by the MCT5 treatment than the PC treatment from d 0 to 14 . Pigs fed PC treatment diet had lower ADFI $(\mathrm{p}<0.05)$ and better FCR $(\mathrm{p}<0.05)$ than NC treatment, whereas no differences were shown between MCT treatments and NC or PC treatment from d 15 to 35 and overall phase. The ATTD of DM and nitrogen were improved ( $<<0.05)$ by the effect of MCT5 related to the $\mathrm{NC}$ and $\mathrm{PC}$ treatment at the end of 2 nd and 5th wk. The pigs fed MCT3 had higher ( $<<0.05)$ energy digestibility than PC treatment. No effects were seen in the blood profiles we measured (WBC, RBC, lymphocyte and immunoglobulin-G). In conclusion, the addition of MCT in the weanling pigs diet can improve the ADG and digestibility during the earlier period (first 2 wks), but had little effect on the blood characteristics. (Key Words: Blood Profile, Digestibility, Growth Performance, Medium-chain-triglyceride (MCT), Pig)
\end{abstract}

\section{INTRODUCTION}

The stress of weaning and the immature development of the digestive tract make newly weaned pigs susceptible to digestive disorders and diarrhea. Due to concern about the feed safety and the development of antibiotic-resistant pathogens, the use of most antibiotic as growth promoters has been banned in the EU since January 2006 (Regulation 1983/2003/EC) and prohibited in July 2011 in Korea. A number of alternative have been proposed: enzymes, probiotics, fermentable carbohydrates (prebiotics), phytogenic agents, and dietary acidifiers (Roth and Kirchgessner, 1998; Partanen and Mroz, 1999).

Midium-chain triglycerides (MCTs) are high-chain (6 to 12 carbons) fatty acid esters of glycerol. The fatty acids found in MCTs are called medium-chain fatty acids

\footnotetext{
* Corresponding Author: In Ho Kim. Tel: +82-41-550-3652, Fax: +82-41-565-2949, E-mail: inhokim@ dankook.ac.kr

${ }^{1}$ Woosung Feed Cormpany, Ltd. Daejeon, Korea. Submitted Nov. 2, 2011; Accepted Jan. 31, 2012; Revised Feb. 6, 2012
}

(MCFAs), such as caproic acid (C6), caprylic acid (C8), capric acid (C10) and lauric acid (C12). They are digested, absorbed and metabolized differently from long-chain fatty acids (LCFAs), which include fatty acids of 12 to 22 carbons, because MCFAs are absorbed directly into portal circulation and transported to the liver for rapid oxidation (Babayan, 1987; Odle, 1998). MCFAs can rapidly supply energy for the newborn piglets (Lee and Chiang, 1994). Gatlin et al. (2002) found that the piglets form sows fed supplemental MCTs had greater ADG and weaning weights by the improving efficiency of energy utilization.

Also, MCFAs were reported to have antibacterial function as the similar way showing by the short-chain fatty acids (Isaacs et al., 1995; Skrivanova et al., 2006). To date there is a general lack of information about the optimum dose of MCT needed in a standard post-weaning diet to cause an antibacterial effect.

Therefore, we conducted 2 experiments to evaluate the effects of the inclusion of MCT in the diet of weanling pigs on growth performance, nutrient digestibility, and blood profile. 


\section{MATERIALS AND METHOD}

The protocol used for the current experiment was approved by the Animal Care and Use Committee of Dankook University.

\section{The preparation of medium-chain triglyceride}

The MCT (AveMix) was prepared and supplied in the form of powder by Aveve Group (Minderbroedersstraat 8, 3000 Leuven, Belgium). The composition of the final product contained 55\% MCT oil (C6: 50\%, C8: 50\%) and Silica carrier $45 \%$.

\section{Experiment design, animals and facilities}

In Exp. 1 and Exp. 2, a total of 120 barrows ((Landrace $\times$ Yorkshire $) \times($ Duroc $))$ with an average BW of $6.91 \pm 0.99 \mathrm{~kg}$ (21 d of age) and $10.20 \pm 1.09 \mathrm{~kg}$ (28 d of age) were used in a 42-d and 35-d experiment. Pigs were randomly allotted to 4 experiment diets according to their initial BW. Each pen held 5 pigs, and there were 6 pens per treatment.

All pigs were housed in an environmentally-controlled room, which provided $0.34 \mathrm{~m}^{2}$ for each pig in Exp. 1 and 2, respectively. Each pen was equipped with a one-sided, stainless steel self-feeder and a nipple drinker that allowed pigs unlimited access to feed and water. Individual pig BW and feed disappearance were recorded weekly for both experiments to determine ADG, ADFI, and feed/gain (F/G).

\section{Dietary treatments}

Both of Exp. 1, and Exp.2 used the same experiment design, following the dietary treatments were: i) negative control (NC), ii) positive control (PC), NC+antibiotics (positive control diet with $40 \mathrm{mg} / \mathrm{kg}$ Tiamulin, $110 \mathrm{ppm}$ Tylosin, and $10 \mathrm{mg} / \mathrm{kg}$ Enramycin. iii) MCT3, NC+0.32\% (phase 1, 2 and 3) medium-chain-triglyceride, and iv) MCT5, NC+0.55\% (phase 1), $0.32 \%$ (phase 2 and 3) medium-chain-triglyceride. The diets were fed during the experiment in 3 phases (Exp. 1) and 2 phases (Exp. 2): d 0 to 14,15 to 28 , and 29 to 42 (Exp. 1) and d 0 to 14,15 to 35 (Exp. 2)

All diets were formulated to meet or exceed the nutrient requirements (NRC, 1998) for weanling pigs and fed in a crumble form. All diets were dried at $100^{\circ} \mathrm{C}$ for $12 \mathrm{~h}$ to determine DM and, then, ground through a 1-mm screen in a Wiley mill before analyzing for $\mathrm{CP}$, $\mathrm{P}$, and $\mathrm{Ca}$ (AOAC, 2000).

\section{Sampling and measurements}

Apparent total tract digestibility (ATTD) of DM nitrogen $(\mathrm{N})$ and gross energy was determined using chromic oxide $(0.2 \%)$ as an inert indicator. Pigs were fed diets mixed with chromic oxide on d 7, 21, and 35 for Exp.
Table 1. Compositions of basal nursery pig diets for Exp. 1 and 2 (as-fed basis)

\begin{tabular}{|c|c|c|c|}
\hline Item & Phase 1 & Phase 2 & Phase 3 \\
\hline Corn & & 44.84 & 43.20 \\
\hline Barley & 15.00 & & \\
\hline Wheat & & & 2.00 \\
\hline Rice bran & & & 2.00 \\
\hline Extrude corn & 47.23 & 25.00 & 15.00 \\
\hline Soybean meal $45 \%$ & 7.50 & 17.00 & 31.81 \\
\hline Fermented soybean meal & 2.50 & & \\
\hline Fish meal & 2.00 & 2.66 & \\
\hline Potato protein & 2.00 & 2.00 & \\
\hline Plasma protein & 3.00 & & \\
\hline Milk product & 10.00 & 3.00 & \\
\hline Milk replacer & 5.00 & & \\
\hline Animal fat & & & 3.32 \\
\hline Soybean oil & 2.50 & 2.37 & \\
\hline DL-met $(99 \%)$ & 0.11 & 0.05 & 0.06 \\
\hline L-lys (78\%) & 0.23 & 0.11 & 0.10 \\
\hline Dicalcium phosphate & 1.18 & 1.07 & 0.62 \\
\hline Salt & 0.25 & 0.40 & 0.40 \\
\hline Premix $^{1}$ & 1.50 & 1.50 & 1.50 \\
\hline \multicolumn{4}{|l|}{ Analyzed composition } \\
\hline $\mathrm{CP}(\%)$ & 19.83 & 19.99 & 19.38 \\
\hline $\mathrm{EE}(\%)$ & 7.56 & 5.93 & 6.00 \\
\hline $\mathrm{CF}(\%)$ & 2.55 & 2.56 & 3.04 \\
\hline Ash (\%) & 5.13 & 4.70 & 4.70 \\
\hline $\mathrm{Ca}(\%)$ & 0.68 & 0.65 & 0.66 \\
\hline $\mathrm{P}(\%)$ & 0.59 & 0.50 & 0.52 \\
\hline Lys (\%) & 1.54 & 1.30 & 1.17 \\
\hline Met $(\%)$ & 0.49 & 0.46 & 0.32 \\
\hline
\end{tabular}

${ }^{1}$ Phase 1: The vitamin and mineral premix supplied per $1 \mathrm{~kg}$ of the diet: $20,000 \mathrm{IU}$ of vitamin A, 3,000 IU of vitamin $\mathrm{D}_{3}, 80 \mathrm{IU}$ of vitamin E, 12 $\mathrm{mg}$ of vitamin $\mathrm{K}, 150 \mathrm{mg}$ of vitamin $\mathrm{C}, 20 \mathrm{mg}$ of riboflavin, $60 \mu \mathrm{g}$ of vitamin $\mathrm{B}_{12}, 50 \mathrm{mg}$ of d-pantothenic acid, $60 \mathrm{mg}$ of biotin, $80 \mathrm{mg}$ of niacin, $2 \mathrm{mg}$ of vitamin $\mathrm{B}_{6}, 110 \mathrm{mg}$ of $\mathrm{Cu}$ from $\mathrm{CuSO}_{4} \cdot 5 \mathrm{H}_{2} \mathrm{O}, 250 \mathrm{mg}$ of $\mathrm{Fe}$ from $\mathrm{FeSO}_{4} \cdot 7 \mathrm{H}_{2} \mathrm{O}, 70 \mathrm{mg}$ of $\mathrm{Mn}$ from $\mathrm{MnO}_{2}, 2,340 \mathrm{mg}$ of $\mathrm{Zn}$ from $\mathrm{ZnO}, 0.2 \mathrm{mg}$ of $\mathrm{Se}$ from $\mathrm{Na}_{2} \mathrm{SeO}_{3} \cdot 5 \mathrm{H}_{2} \mathrm{O}, 0.3 \mathrm{mg}$ of $\mathrm{Co}$ from $\mathrm{CoSO}_{4} \cdot 7 \mathrm{H}_{2} \mathrm{O}$. Phase 2 : The vitamin and mineral premix supplied per $1 \mathrm{~kg}$ of the diet: $15,000 \mathrm{IU}$ of vitamin A, 2,500 IU of vitamin $\mathrm{D}_{3}, 60 \mathrm{IU}$ of vitamin E, $10 \mathrm{mg}$ of vitamin $\mathrm{K}, 150 \mathrm{mg}$ of vitamin C, $15 \mathrm{mg}$ of riboflavin, $50 \mu \mathrm{g}$ of vitamin $\mathrm{B}_{12}, 40 \mathrm{mg}$ of d-pantothenic acid, $60 \mathrm{mg}$ of biotin, $80 \mathrm{mg}$ of niacin, $2 \mathrm{mg}$ of vitamin $\mathrm{B}_{6}, 110 \mathrm{mg}$ of $\mathrm{Cu}$ from $\mathrm{CuSO}_{4} \cdot 5 \mathrm{H}_{2} \mathrm{O}, 250 \mathrm{mg}$ of $\mathrm{Fe}$ from $\mathrm{FeSO}_{4} \cdot 7 \mathrm{H}_{2} \mathrm{O}, 70 \mathrm{mg}$ of $\mathrm{Mn}$ from $\mathrm{MnO}_{2}, 2,340 \mathrm{mg}$ of $\mathrm{Zn}$ from $\mathrm{ZnO}, 0.2 \mathrm{mg}$ of Se from $\mathrm{Na}_{2} \mathrm{SeO}_{3} \cdot 5 \mathrm{H}_{2} \mathrm{O}, 0.3$ mg of $\mathrm{Co}$ from $\mathrm{CoSO}_{4} \cdot 7 \mathrm{H}_{2} \mathrm{O}$. Phase 3: The vitamin and mineral premix supplied per $1 \mathrm{~kg}$ of the diet: 10,000 IU of vitamin A, 2,000 IU of vitamin $\mathrm{D}_{3}, 40 \mathrm{IU}$ of vitamin $\mathrm{E}, 8 \mathrm{mg}$ of vitamin $\mathrm{K}, 100 \mathrm{mg}$ of vitamin $\mathrm{C}$, $10 \mathrm{mg}$ of riboflavin, $50 \mu \mathrm{g}$ of vitamin $\mathrm{B}_{12}, 30 \mathrm{mg}$ of d-pantothenic acid, $50 \mathrm{mg}$ of biotin, $60 \mathrm{mg}$ of niacin, $2 \mathrm{mg}$ of vitamin $\mathrm{B}_{6}, 110 \mathrm{mg}$ of $\mathrm{Cu}$ from $\mathrm{CuSO}_{4} \cdot 5 \mathrm{H}_{2} \mathrm{O}, 120 \mathrm{mg}$ of $\mathrm{Fe}$ from $\mathrm{FeSO}_{4} \cdot 7 \mathrm{H}_{2} \mathrm{O}, 50 \mathrm{mg}$ of $\mathrm{Mn}$ from $\mathrm{MnO}_{2}, 2,340 \mathrm{mg}$ of $\mathrm{Zn}$ from $\mathrm{ZnO}, 0.2 \mathrm{mg}$ of Se from $\mathrm{Na}_{2} \mathrm{SeO}_{3} \cdot 5 \mathrm{H}_{2} \mathrm{O}, 0.5$ $\mathrm{mg}$ of $\mathrm{Co}$ from $\mathrm{CoSO}_{4} \cdot 7 \mathrm{H}_{2} \mathrm{O}$.

1 and $\mathrm{d} 7$ and 28 for Exp. 2. Fresh fecal grab samples collected from 2 pigs per pen (Exp. 1, d 13, 27 and 41; Exp. 2, d 13, and 34) were mixed and pooled, and a representative sample was stored in a freezer at $-20^{\circ} \mathrm{C}$ until 
Table 2. Effect of medium-chain-triglyceride on performance of weanling pigs (Exp. 1) ${ }^{1}$

\begin{tabular}{|c|c|c|c|c|c|}
\hline Items & $\mathrm{NC}$ & $\mathrm{PC}$ & MCT3 & MCT5 & $\mathrm{SE}^{2}$ \\
\hline \multicolumn{6}{|c|}{0 to $14 \mathrm{~d}$ (phase 1$)$} \\
\hline $\mathrm{ADG}(\mathrm{g})$ & $239^{\mathrm{b}}$ & $279^{\mathrm{ab}}$ & $272^{\mathrm{ab}}$ & $293^{\mathrm{a}}$ & 14 \\
\hline ADFI (g) & 274 & 298 & 299 & 335 & 20 \\
\hline $\mathrm{F} / \mathrm{G}$ & 1.146 & 1.068 & 1.099 & 1.205 & 0.08 \\
\hline \multicolumn{6}{|c|}{15 to $28 \mathrm{~d}$ (phase 2 ) } \\
\hline $\operatorname{ADG}(\mathrm{g})$ & 481 & 432 & 438 & 476 & 23 \\
\hline ADFI (g) & 727 & 677 & 677 & 715 & 31 \\
\hline $\mathrm{F} / \mathrm{G}$ & 1.511 & 1.567 & 1.546 & 1.502 & 0.141 \\
\hline \multicolumn{6}{|c|}{29 to $42 \mathrm{~d}$ (phase 3 ) } \\
\hline $\mathrm{ADG}(\mathrm{g})$ & 542 & 550 & 560 & 535 & 47 \\
\hline ADFI (g) & 960 & 886 & 879 & 888 & 36 \\
\hline $\mathrm{F} / \mathrm{G}$ & 1.771 & 1.611 & 1.570 & 1.660 & 0.156 \\
\hline \multicolumn{6}{|c|}{0 to $42 \mathrm{~d}$ (Overall phase) } \\
\hline $\mathrm{ADG}(\mathrm{g})$ & 426 & 420 & 422 & 436 & 18 \\
\hline ADFI (g) & 644 & 621 & 616 & 643 & 22 \\
\hline $\mathrm{F} / \mathrm{G}$ & 1.512 & 1.479 & 1.460 & 1.475 & 0.072 \\
\hline
\end{tabular}

${ }_{\mathrm{a}, \mathrm{b}}$ Within a row, mean with different superscripts differ $(\mathrm{p}<0.05)$.

${ }^{1}$ Each mean represents 6 pens with 5 pigs each per treatment. Dietary treatments were as follows: $\mathrm{NC}=$ Negative control diet; $\mathrm{PC}=\mathrm{Positive}$ control diet with $40 \mathrm{mg} / \mathrm{kg}$ Tiamulin, $110 \mathrm{ppm}$ Tylosin, and $10 \mathrm{mg} / \mathrm{kg}$ Enramycin. MCT3 = NC+0.32\% medium-chain-triglyceride. MCT5 = NC+0.55\% (phase 1), $0.32 \%$ (phase 2,3 ) medium-chain-triglyceride.

${ }^{2}$ Standard errors.

analyzed. Before chemical analysis, the fecal samples were thawed and dried at $50^{\circ} \mathrm{C}$ for $72 \mathrm{~h}$, after which they were finely ground to a size that could pass through a $1-\mathrm{mm}$ screen. All feed and fecal samples were, then, analyzed for $\mathrm{DM}$ and $\mathrm{N}$ following the procedures outlined by the AOAC (1995). Chromium was analyzed via UV absorption spectrophotometry (Shimadzu, UV-1201, Shimadzu, Kyoto, Japan) following the method described by Williams et al. (1962).

For the serum profile, 2 pigs ( 1 gilt and 1 barrow) from each pen were randomly selected and blood samples were collected via anterior vena cava puncture on $\mathrm{d} 0,14,28$, and 42 for Exp. 1 and d 0,14 and 35 for the Exp. 2. At the time of collection, blood samples were collected into both nonheparinized tubes and vacuum tubes containing $\mathrm{K}_{3}$ EDTA (Becton, Dickinson and Co., Franklin Lakes, NJ, USA) to obtain serum and whole blood, respectively. After collection, serum samples were centrifuged $(2,000 \times g)$ for $30 \mathrm{~min}$ at $4^{\circ} \mathrm{C}$. Serum total protein was determined using an automatic biochemistry analyzer (HITACHI 747, Hitachi, Tokyo, Japan). Serum immunoglobulin-G (IgG) was analyzed using nephelometry (Dade Behring, Marburg, Germany). The white blood cells (WBC), red blood cells (RBC) and lymphocyte percentage in the whole white blood were determined using an automatic blood analyzer (ADVIA 120, Bayer, NY, USA).

\section{Statistical analysis}

All data were subjected to statistical analysis in a randomized complete block design using the GLM procedures (SAS, 2001), with the pen serving as the experimental unit. Duncan's multiple range test was used to compare the means of the treatments. Variability in the data is expressed as the standard error (SE) and probability level of $\mathrm{p}<0.05$ was considered to be statistically significant.

\section{RESULTS}

\section{Experiment 1}

Growth performance: The growth performance data are presented in Table 2. The ADG were higher in MCT5 treatment than $\mathrm{NC}$ treatment during phase $1(\mathrm{p}<0.05)$. There were no differences in ADG, ADFI and FCR among treatments ( $p>0.05)$ during phase 2 and overall period.

The ATTD of DM, nitrogen, and gross energy: From 15 to $28 \mathrm{~d}$, the ATTD of energy was higher $(\mathrm{p}<0.05)$ in $\mathrm{NC}$ and MCT3 treatments than PC treatment (Table 3). No difference has been observed on the nutrients digestibility during d 0 to 14 and d 29 to 42 .

Blood characteristics: No differences were shown in WBC, RBC, IgG, and lymphocyte concentration among treatments throughout the experiment (Table 4).

\section{Experiment 2}

Growth performance: The pigs fed diet containing MCT5 had a higher $(\mathrm{p}<0.05)$ ADG than those fed PC diet during phase 1. For phase 2, the ADFI was higher $(p<0.05)$ in NC treatment than PC treatment, where the ADG didn't differ among treatments, which led to a depression $(p<0.05)$ in FCR when compare to PC treatment. MCT improved FCR $(\mathrm{p}<0.05)$ in the overall phase when compared to the no antibiotics treatment. 
Table 3. Effect of medium-chain-triglyceride on apparent total tract nutrient digestibility (ATTD) of weanling pigs (Exp. 1) ${ }^{1}$

\begin{tabular}{lccccc}
\hline Items & NC & PC & MCT3 & MCT5 & SE $^{2}$ \\
\hline 0 to 14 d (phase 1) & & & & & \\
$\quad$ DM & 78.13 & 78.48 & 79.65 & 79.56 & 0.61 \\
Nitrogen & 78.63 & 78.64 & 78.67 & 78.86 & 0.79 \\
Gross energy & 79.79 & 80.99 & 80.24 & 79.85 & 0.67 \\
15 to 28 d (phase 2) & & & & & \\
DM & 78.84 & 77.23 & 78.66 & 78.51 & 0.73 \\
Nitrogen & 78.44 & 76.95 & 78.30 & 78.08 & 0.80 \\
Energy & $80.36^{\mathrm{a}}$ & $78.00^{\mathrm{b}}$ & $80.38^{\mathrm{a}}$ & $78.53^{\mathrm{ab}}$ & 0.72 \\
29 to 42 d (phase 3) & & & & & \\
DM & 78.99 & 79.72 & 79.45 & 80.45 & 0.68 \\
$\quad$ Nitrogen & 78.20 & 79.15 & 78.67 & 79.49 & 0.56 \\
Gross energy & 78.86 & 79.00 & 78.75 & 80.60 & 0.92 \\
\hline
\end{tabular}

${ }^{\mathrm{a}, \mathrm{b}}$ Within a row, mean with different superscripts differ $(\mathrm{p}<0.05)$.

${ }^{1}$ Each mean represents 6 pens with 5 pigs each per treatment. Dietary treatments were as follows: $\mathrm{NC}=$ Negative control diet; $\mathrm{PC}=$ Positive control diet with $40 \mathrm{mg} / \mathrm{kg}$ Tiamulin, $110 \mathrm{ppm}$ Tylosin, and $10 \mathrm{mg} / \mathrm{kg}$ Enramycin. MCT3 $=\mathrm{NC}+0.32 \%$ medium-chain-triglyceride. $\mathrm{MCT} 5=$ $\mathrm{NC}+0.55 \%$ (phase 1 ), $0.32 \%$ (phase 2,3 ) medium-chain-triglyceride.

${ }^{2}$ Standard errors.

The ATTD of DM, nitrogen, and gross energy: Throughout the experimental period, the ATTD of DM, and of nitrogen were enhanced $(\mathrm{p}<0.05)$ by MCT5 treatment when compared to PC, and NC treatments, whereas the energy digestibility was higher $(\mathrm{p}<0.05)$ in both MCT3 and MCT5 treatments than PC treatment.

Blood characteristics: For blood profiles, WBC, RBC, $\mathrm{IgG}$, and lymphocyte concentration were not different among treatments throughout the experiment.

\section{DISCUSSION}

In this study, MCT was found to improve the ADG for
Table 4. Effect of medium-chain-triglyceride on blood characteristics of weanling pigs at $\mathrm{d} 42$ (Exp. 1) ${ }^{1}$

\begin{tabular}{|c|c|c|c|c|c|}
\hline Items & $\mathrm{NC}$ & $\mathrm{PC}$ & MCT3 & MCT5 & $\mathrm{SE}^{2}$ \\
\hline \multicolumn{6}{|c|}{$\operatorname{WBC}\left(10^{3} / \mu \mathrm{l}\right)$} \\
\hline $0 \mathrm{~d}$ & 12.26 & 12.26 & 12.26 & 12.26 & - \\
\hline $14 \mathrm{~d}$ & 14.38 & 13.87 & 14.78 & 14.83 & 1.09 \\
\hline $28 \mathrm{~d}$ & 14.40 & 14.25 & 15.96 & 16.20 & 0.78 \\
\hline $42 \mathrm{~d}$ & 18.62 & 19.27 & 17.49 & 17.86 & 0.65 \\
\hline \multicolumn{6}{|c|}{$\operatorname{RBC}\left(10^{6} / \mu \mathrm{l}\right)$} \\
\hline $0 \mathrm{~d}$ & 5.38 & 5.38 & 5.38 & 5.38 & - \\
\hline $14 \mathrm{~d}$ & 5.83 & 5.58 & 5.68 & 5.62 & 0.21 \\
\hline $28 \mathrm{~d}$ & 6.45 & 6.14 & 6.08 & 6.04 & 0.21 \\
\hline $42 \mathrm{~d}$ & 7.07 & 7.09 & 6.82 & 6.83 & 0.13 \\
\hline \multicolumn{6}{|c|}{ Lymphocyte $^{3}(\%)$} \\
\hline $0 \mathrm{~d}$ & 55.5 & 55.5 & 55.5 & 55.5 & - \\
\hline $14 \mathrm{~d}$ & 55.6 & 56.8 & 60.7 & 57.1 & 2.99 \\
\hline $28 \mathrm{~d}$ & 60.0 & 59.5 & 63.8 & 63.2 & 3.59 \\
\hline $42 \mathrm{~d}$ & 57.9 & 59.3 & 60.7 & 57.6 & 1.6 \\
\hline \multicolumn{6}{|c|}{$\operatorname{IgG}(\mathrm{mg} / \mathrm{dl})$} \\
\hline $0 \mathrm{~d}$ & 207 & 207 & 207 & 207 & - \\
\hline $14 \mathrm{~d}$ & 277 & 302 & 268 & 274 & 18.2 \\
\hline $28 \mathrm{~d}$ & 354 & 414 & 384 & 368 & 48.4 \\
\hline $42 \mathrm{~d}$ & 498 & 553 & 491 & 510 & 47.5 \\
\hline
\end{tabular}

${ }^{\mathrm{a}, \mathrm{b}}$ Within a row, mean with different superscripts differ $(\mathrm{p}<0.05)$.

${ }^{1}$ Each mean represents 6 pens with 5 pigs each per treatment. Dietary treatments were as follows: $\mathrm{NC}=$ Negative control diet; $\mathrm{PC}=$ Positive control diet with $40 \mathrm{mg} / \mathrm{kg}$ Tiamulin, $110 \mathrm{ppm}$ Tylosin, and $10 \mathrm{mg} / \mathrm{kg}$ Enramycin. MCT3 $=$ NC+0.32\% medium-chain-triglyceride. MCT5 = $\mathrm{NC}+0.55 \%$ (phase 1), $0.32 \%$ (phase 2,3 ) medium-chain-triglyceride.

${ }^{2}$ Standard errors.

${ }^{3}$ Values are presented as a percentage of total white blood cell count.

the first 2 wk of post-weaning, which is similar (Exp. 1) or better (Exp. 2) with the weaning pigs fed antibiotics. Similarly, Rodas and Maxwell (1992) reported that MCFAs (20 to $60 \mathrm{~g} / \mathrm{kg}$ ) inclusion can linearly enhance ADG and $\mathrm{G} / \mathrm{F}$ for weaning pigs during the first weeks after

Table 5. Effect of medium-chain-triglyceride on growth performance of weanling pigs (Exp. 2) ${ }^{1}$

\begin{tabular}{lccccc}
\hline Items & NC & PC & MCT3 & MCT5 & SE $^{2}$ \\
\hline 0 to 14 d (phase 1) & & & & & \\
ADG (g) & $490^{\mathrm{ab}}$ & $476^{\mathrm{b}}$ & $517^{\mathrm{ab}}$ & $521^{\mathrm{a}}$ & 14 \\
ADFI (g) & 609 & 620 & 628 & 661 & 21 \\
F/G & 1.243 & 1.303 & 1.215 & 1.269 & 0.046 \\
15 to 35 d (phase 2) & & & & \\
ADG (g) & 625 & 636 & 635 & 641 & 13 \\
ADFI (g) & $1,095^{\mathrm{a}}$ & $1,000^{\mathrm{b}}$ & $1,043^{\mathrm{ab}}$ & $1,045^{\mathrm{ab}}$ & 27 \\
F/G & $1.752^{\mathrm{a}}$ & $1.572^{\mathrm{b}}$ & $1.643^{\mathrm{ab}}$ & $1.630^{\mathrm{ab}}$ & 0.04 \\
0 to 35 d (Overall phase) & & & & 593 & 8 \\
ADG (g) & 571 & 572 & 590 & 891 & 1.503 \\
ADFI (g) & 901 & 848 & 1.486 & 0.031 \\
F/G & 1.578 & 1.483 & & \\
\hline
\end{tabular}

${ }_{\mathrm{a}, \mathrm{b}}$ Within a row, mean with different superscripts differ $(\mathrm{p}<0.05)$

${ }^{1}$ Each mean represents 6 pens with 5 pigs each per treatment. Dietary treatments were as follows: NC = Negative control diet; PC $=$ Positive control diet with $40 \mathrm{mg} / \mathrm{kg}$ Tiamulin, $110 \mathrm{mg} / \mathrm{kg}$ Tylosin, and $10 \mathrm{mg} / \mathrm{kg}$ Enramycin. MCT3 = NC+0.32\% medium-chain-triglyceride. MCT5 = NC+0.55\% (phase 1), $0.32 \%$ (phase 2,3 ) medium-chain-triglyceride.

${ }^{2}$ Standard errors. 
Table 6. Effect of medium-chain-triglyceride on apparent total tract nutrient digestibility (ATTD) of weanling pigs (Exp. 2) ${ }^{1}$

\begin{tabular}{lccccc}
\hline Items & NC & PC & MCT3 & MCT5 & SE $^{2}$ \\
\hline 0 to 14 d & & & & & \\
DM & $78.76^{\mathrm{b}}$ & $78.79^{\mathrm{b}}$ & $79.53^{\mathrm{ab}}$ & $80.82^{\mathrm{a}}$ & 0.502 \\
Nitrogen & $78.99^{\mathrm{b}}$ & $78.90^{\mathrm{b}}$ & $80.19^{\mathrm{ab}}$ & $81.62^{\mathrm{a}}$ & 0.613 \\
Gross energy & $80.41^{\mathrm{ab}}$ & $79.58^{\mathrm{b}}$ & $81.87^{\mathrm{a}}$ & $81.77^{\mathrm{a}}$ & 0.620 \\
15 to 35 d & & & & & \\
DM & $79.39^{\mathrm{b}}$ & $79.00^{\mathrm{b}}$ & $79.70^{\mathrm{ab}}$ & $79.99^{\mathrm{a}}$ & 0.501 \\
Nitrogen & $80.50^{\mathrm{b}}$ & $79.48^{\mathrm{b}}$ & $79.85^{\mathrm{ab}}$ & $80.77^{\mathrm{a}}$ & 0.613 \\
Gross energy & $80.13^{\mathrm{ab}}$ & $79.86^{\mathrm{b}}$ & $79.94^{\mathrm{a}}$ & $80.48^{\mathrm{a}}$ & 0.621 \\
\hline
\end{tabular}

${ }_{\mathrm{a}, \mathrm{b}}$ Within a row, mean with different superscripts differ $(\mathrm{p}<0.05)$.

${ }^{1}$ Each mean represents 6 pens with 5 pigs each per treatment. Dietary treatments were as follows: $\mathrm{NC}=$ Negative control diet; $\mathrm{PC}=$ Positive control diet with $40 \mathrm{mg} / \mathrm{kg}$ Tiamulin, $110 \mathrm{ppm}$ Tylosin, and $10 \mathrm{mg} / \mathrm{kg}$ Enramycin. MCT3 = NC+0.32\% medium-chain-triglyceride. MCT5 = $\mathrm{NC}+0.55 \%$ (phase 1 ), $0.32 \%$ (phase 2,3 ) medium-chain-triglyceride.

${ }^{2}$ Standard errors.

supplementation, which had a greater effect than tallow or milk fat. One of the reason is the that piglet can utilize MCFAs effectively, which can be easily digested and absorbed to supply energy by oxidation (Odle et al., 1989; Odle et al., 1991). The explanation for MCFAs being absorbed faster than long-chain fatty acid are (LCFA): i) esterification of MCFAs is low and most MCFAs can be directly absorbed without hydrolysis by lipase; ii) MCFAs enter the liver directly and rapidly via the portal vein, whereas LCFAs first enter the blood and then into a variety of tissues via the lymph system; iii) glycerides composed of MCFAs can be hydrolyzed faster and more completely and have a higher digestibility and faster clearing from the circulation and iv) MCFAs can be dispersed relatively easily in water and the ratio of re-esterification into chyle particles is low, thus MCFAs and their glycerides are mostly dispersed in intestinal solution and cell membranes and can be absorbed without particle formation (Odle, 1998).

The other explanation may be that the MCFAs were reported to exert antimicrobial activity that can reduce the pathogenic flora of the gut, which would have beneficial effects on the utilization of nutrients. Bacteria need nutrients for their own use and compete with the host for nutrients in the stomach and small intestine. In pigs, caproic (hexanioc) acid also was reported to depress the growth of Lactobacillus and Steptococcus spp., while capric (decanoic) and lauric (C12) acids only depressed Lactobacillus and Streptococcus spp. The results from these previous studies also confirm that the positive effects of MCFA on digestibility and growth performance are a result of successful inhibition of the proliferation of pathogenic bacteria. However, there are contrary findings. Chi and Lepine (1993) supplemented the diets of piglets weaned at 3 weeks old with $100 \mathrm{~g}$ maize oil, coconut oil, tallow or
Table 7. Effect of medium-chain-triglyceride on blood characteristics of weanling pigs at d 35 (Exp. 2) ${ }^{1}$

\begin{tabular}{lccccc}
\hline Items & NC & PC & MCT3 & MCT5 & SE $^{2}$ \\
\hline WBC $\left(10^{3} / \mu \mathrm{l}\right)$ & & & & & \\
$0 \mathrm{~d}$ & 17.82 & 17.82 & 17.82 & 17.82 & - \\
$14 \mathrm{~d}$ & 17.35 & 19.18 & 19.79 & 19.57 & 1.13 \\
$35 \mathrm{~d}$ & 20.97 & 21.72 & 20.69 & 20.84 & 0.99 \\
$\mathrm{RBC}\left(10^{6} / \mu \mathrm{l}\right)$ & & & & & \\
$0 \mathrm{~d}$ & 5.74 & 5.74 & 5.74 & 5.74 & - \\
$14 \mathrm{~d}$ & 6.14 & 6.28 & 6.25 & 6.44 & 0.16 \\
$35 \mathrm{~d}$ & 7.20 & 7.19 & 7.15 & 7.19 & 0.16 \\
Lymphocyte & & & & \\
$0 \mathrm{~d}$ & & & & & \\
$14 \mathrm{~d}$ & 46.5 & 46.5 & 46.5 & 46.5 & - \\
$35 \mathrm{~d}$ & 65.3 & 64.1 & 64.9 & 64.6 & 1.75 \\
IgG (mg/dl) & 54.1 & 56.7 & 52.1 & 55.7 & 2.40 \\
$0 \mathrm{~d}$ & 234 & 234 & 234 & 234 & - \\
$14 \mathrm{~d}$ & 221 & 260 & 240 & 237 & 24.7 \\
$35 \mathrm{~d}$ & 360 & 366 & 405 & 370 & 32
\end{tabular}

${ }^{\mathrm{a}, \mathrm{b}}$ Within a row, mean with different superscripts differ $(\mathrm{p}<0.05)$.

${ }^{1}$ Each mean represents 6 pens with 5 pigs each per treatment. Dietary treatments were as follows: $\mathrm{NC}=$ Negative control diet; $\mathrm{PC}=$ Positive control diet with $40 \mathrm{mg} / \mathrm{kg}$ Tiamulin, $110 \mathrm{ppm}$ Tylosin, and $10 \mathrm{mg} / \mathrm{kg}$ Enramycin. MCT3 $=$ NC+0.32\% medium-chain-triglyceride. MCT5 = $\mathrm{NC}+0.55 \%$ (phase 1 ), $0.32 \%$ (phase 2,3 ) medium-chain-triglyceride. ${ }^{2}$ Standard errors.

MCFAs/kg 3 wks and found that the MCFA group had the lowest ADG of all the treatments. Fakler et al. (1993) also suggested that supplementing the diets of weanling piglets with $80 \mathrm{~g} \mathrm{MCFAs} \mathrm{or} \mathrm{coconut} \mathrm{oil} / \mathrm{kg}$ resulted in ADG to decrease significantly first week postweaning compared with piglets given soya bean oil or tallow. These inconsistent results may be attributed to the quality and supplementation levels of the fats used.

Moreover, MCT are used directly for the acylmodification (activation) of ghrelin within the gut of rats (Nishi et al., 2005). Ghrelin is primarily produced by endocrine cells of the gastric mucosa for secretion into the circulation. Studies have identified multiple physiological functions for ghrelin, including growth hormone $(\mathrm{GH})$ release, appetite stimulation, cellular proliferation, apoptosis inhibition, and regulation of lipid metabolism and tissue fat distribution in muscle (Nishi et al., 2005). Ghrelin is also reported to be involved in the inhibition of proinflammatory cytokine production and gastro-protection against stress-induced gastric damage in rats (Konturek et al., 2004). Furthermore, exogenous ghrelin administration for 5 days to 18 day-old weaned pigs increased their weight gain (Salfen et al., 2004).

The feed intake of weanling pigs was unaffected by the MCT addition in the current study. However, Dierick et al. (2002) reported that lower feed intake occurred when Cuphea seeds (80\% is capric acid C10:0) were added at 50 
$\mathrm{g} / \mathrm{kg}$. This may due to the different dosage and composition of MCFAs used in these investigations. It is said that the high levels of free MCFA with a known strong rancid (C4: 0-C6:0), goat-like (C8:0), goat-cheesy (C8:0) and averse taste most probably should have resulted in a lower feed intake (Cera et al., 1989). This may due to the different levels used in these investigations.

None of the metabolites measured in blood indicated a difference caused by MCT and improved the energy status of pigs, The gastrointestinal system and its associated lymphoid tissue is the largest immunologically competent organ in the body, and maturation and optimal development of the immune system after birth depends on the development and composition of the indigenous microflora and vice versa (Michael and Marteau, 2007). Although the action of organic acid on the immune responses has not been well documented, it has been clearly established that many types of organic acids can influence the population of gut intestinal microorganisms, which are necessary for development of the gut immune system (Blum et al., 2002). In addition, a reduction in subclinical infections because of antimicrobial effects may contribute to improved nutrient digestibility and a reduction in the demand for nutrients by the gut-associated immune tissue.

\section{REFERENCES}

AOAC. 2000. Official methods of analysis. 17th ed. Assoc. Off. Anal. Chem., Gaithersburg, MD.

Babayan, V. K. 1987. Medium-chain triglycerides and structured lipids. Lipids 22:417-420.

Blum, S., D. Haller, A. Pfeifer and E. J. Schiffrin. 2002. Probiotics and immune responses. Clin. Rev. Allergy Immunol. 22:287309.

Cera, K., D. Mahan and G. Reinhart. 1989. Postweaning swine performance and serum profile responses to supplemental medium-chain free fatty acids and tallow. J. Anim. Sci. 67:2048-2055.

Chi, F. and A. J. Lepine. 1993. Effect of dietary lipid on growth performance and fatty acid binding protein activity in the liver and small intestine of the weanling pig. J. Anim. Sci. 71:178.

Dierick, N. A., J. A. Decuypere and I. Degeyter. 2002. The combined use of whole Cuphea seeds containing medium chain fatty acids and an exogenous lipase in piglet nutrition. Arch. Anim. Nutr. 57:49-63.

Fakler, T. M., C. M. Adams and C. V. Maxwell. 1993. Effect of dietary fat source on performance and fatty acid absorption in the early-weaned pig. J. Anim. Sci. 71:174.
Gatlin, L. A., J. Odle, J. Soede and J. A. Hansen. 2004. Dietary medium- or long-chain triglycerides improve body condition of lean- genotype sows and increase suckling pig growth. J. Anim. Sci. 80:38-44.

Isaacs, C. E., R. E. Litov and H. Thormar. 1995. Antimicrobial activity of lipids added to human milk, infant formula, and bovine milk. J. Nutr. Biochem. 6:362-366.

Konturek, P. C., T. Brzozowski and R. Pajdo. 2004. Ghrelin - a new gastroprotective factor in gastric mucosa. J. Physiol. Pharmacol. 55:325-336.

Lee, H. F. and S. H. Chiang. 1994. Energy value of medium-chain triglycerides and their efficacy in improving survival of neonatal pigs. J. Anim. Sci. 72:133-138.

Michael de, V. and P. R. Marteau. 2007. Probiotics and prebiotics: effects on diarrhea. J. Nutr. 137:803-811.

NRC. 1998. Nutrient requirements of swine. 10th rev. ed. Natl. Acad. Press, Washington, DC, USA.

Nishi, Y., H. Hiejima, H. Hosoda, H. Kaiya, K. Mori, Y. Fukue, T. Yanase, H. Nawata, K. Kangawa and M. Kojima. 2005. Ingested medium-chain fatty acids are directly utilized for the acyl modification of ghrelin. Endocrinology 146:2255-2264.

Odle, J. 1998. Medium-chain triglycerides: a unique energy source for neonatal pigs. Pig News Info. 20:25N-32N.

Odle, J., N. J. Benevenga and T. D. Crenshaw. 1989. Utilization of medium-chain triacylglycerols by neonatal piglets. 2. Effects of even-and odd-chain triglyceride consumption over the first 2 days of life on blood metabolites and urinary nitrogen excretion. J. Anim. Sci. 67:3340-3351.

Odle, J., N. J. Benevenga and T. D. Crenshaw. 1991. Postnatal age and the metabolism of medium- and long-chain fatty acids by isolated hepatocytes from small-for-gestational-age and appropriate-for-gestational-age piglets. J. Nutr. 121:615-621.

Partanen, K. and Z. Mroz. 1999. Organic acids for performance enhancement in pig diets. Nutr. Res. Rev. 12:117-145.

Rodas, B. D. and C. V. Maxwell. 1992. The effect of fat source and medium-chain triglyceride level on performance of the early-weaned pig. Pig News Info.13:273.

Roth, F. X. and M. Kirchgessner. 1998. Organic acids as feed additives for young pigs: Nutritional and gastrointestinal effects. J. Anim. Feed Sci. 7:25-33.

Salfen, B. E., J. A. Carroll, D. H. Keisler and T. A. Strauch. 2004. Effects of exogenous ghrelin on feed intake, weight gain, behavior, and endocrine responses in weanling pigs. J. Anim. Sci. 82:1957-1966.

SAS Institute. 2001. SAS user's guide. Version 8 ed.SAS Inst. Inc., Cary NC.

Skrivanova, E., M. Marounek, V. Benda and P. Brezinia. 2006. Susceptibility of escherichia coli, salmonella sp. and clostridium perfringens to organic acids and monolaurin. Vet. Med-Czech. 51:81-88

Williams, C. H., D. J. David and O. Iismaa. 1962. The determination of chromic oxide in faeces samples by atomic absorption spectrophotometery. J. Agric. Sci. 59:381-385. 